\title{
Ecological Aspects and Policy Impact on Expansion of Poultry Production in Ireland (1995-2014)
}

\author{
AKM Sarwar Inam ${ }^{1}$, Md Suzauddula ${ }^{2}$ and John Kearney ${ }^{3}$ \\ ${ }^{1}$ Assistant Professor, Department of Nutrition and Food Engineering, Daffodil International University, Dhaka-1207, Bangladesh \\ ${ }^{2}$ Research Associate, Department of Nutrition and Food Engineering, Daffodil International University, Dhaka-1207, Bangladesh \\ ${ }^{3}$ Lecturer, Dublin Institute of Technology, Kevin Street, Dublin 2, D08 X622, Ireland \\ *Corresponding author's Email: suzauddula34-506@ diu.edu.bd; ORCiD: 0000-0003-4475-8393
}

Received: 20 Feb 2019

Accepted: 22 Mar 2019

\begin{abstract}
Poultry meat is very popular in Ireland because of low cholesterol level. Ireland is in the top position for the consumption of poultry meat in whole Europe. Ireland emits $3.3 \mathrm{~kg} \mathrm{CO} 2$ - equivalent per $\mathrm{kg}$ of poultry for the poultry meat production which is the lowest amount among all the other European countries. To expand this sector with respect to environmental concern some issues need to be considered very carefully such as effective poultry feed production system, energy consumption in both poultry production and processing area, manure management system, wastewater and odour management systems. If these issues are not handled carefully, several types of harmful effect will occur in both living and environment cycle such as water borne diseases, global warming and ozone layer depletion. The objective of this report is to give an overview of the current situation of poultry production in Ireland, policies and legislation related to poultry production and to show the way to expand this sector in Ireland in line with current ecological concern.
\end{abstract}

Keywords: Ecological and policy, Management of poultry-waste, Poultry and environment, Poultry production

\section{INTRODUCTION}

Recently the department of agriculture, food and the marine announced that about 24 billion euro comes from agri-food sector in Ireland, and in the national economy, $6.3 \%$ gross value added, $10 \%$ of Ireland's total exports and $7.7 \%$ of total national employment are contributed by this sector (Teagasc, 2012). By exporting chicken in 2014 Ireland earned 310 million euro and in 2015 the earning increased to 320 million euro (Bia, 2016). The Irish poultry industry is a very important contributor to the agriculture and economies of Ireland. This industry is growing very fast. The annual consumption of poultry meat has been almost doubled between 1980 and 2000 (FAO, 2009). In the European Union, Ireland was the highest position in per capita consumption of poultry meat (McCarthy et al., 2004).

The poultry industries were contributing a lot to meet the increasing need for the cheapest and safe supply of meat and eggs since last decade (Kearney, 2010). Many new changes happened in this growing sector such as structural changes, land independent farming, intense productions etc. The main intention was to decrease the production cost and increasing supply which have been done by improving animal genetics, optimized nutrition, efficient operations and new integrated technologies (Paul, 2010). All these things have given rise to environmental concerns. This is now not only limited to production area but also amplify to environmental problems at local and global scales. Globally greenhouse gas emissions are one of the main problems in the world. The emission sources can be categorized as i) feed production, using for fertilizers to produce feed and even production processes of that fertilizer, ii) on-farm energy consumption, iii) energy consumption for transporting poultry or poultry feed, iv) emission from manure management system, v) energy consumption in poultry processing area, vi) emission from waste or by-product of poultry processing. Mainly six gases are responsible for greenhouse gases. They are $\mathrm{CO}_{2}, \mathrm{CH}_{4}, \mathrm{~N}_{2} \mathrm{O}$, hydrofluorocarbon, perfluorocarbon and sulphur hexafluoride (IOPC, 2007). 
The emission of first three (carbon-dioxide, methane, nitrous oxide) are higher for faecal matter and the concentrations depend on the ventilation efficiency and rate (JRC, 2010). In Ireland, the carbon footprint of poultry and egg production is low compared to other European countries. But from the ecological point of view in growing and to expand the poultry sector in Ireland utmost concern should be given at this field. In this review, current situation of poultry production along with European and Irish policies and legislation, carbon footprint, environmental issues and the prevention of the poultry waste with the expansion of this sector are discussed.

\section{Poultry production in Ireland}

In Ireland, four systems are maintained for poultry production. Those are intensive (commercial), free-range, label rouge and organic. Main differences between these production systems are shown in table 2 (Lampkin, 1997).

Table 2. Differences between poultry production systems-March 1997, Ireland

\begin{tabular}{|c|c|c|c|}
\hline \multirow{2}{*}{ Production System } & \multicolumn{2}{|l|}{ (a)Intensive } & \multirow{2}{*}{$\begin{array}{l}\text { (b)Extensive } \\
\text { Organic }^{2}\end{array}$} \\
\hline & Broiler $^{1}$ & Free range table birds ${ }^{1}$ & \\
\hline Minimum age at slaughter (days) & None, generally $39-45$ days & 56 (days) & 81 (days) if not slow growing \\
\hline Breed specification & None & None & None as such, but slow growing preferred \\
\hline $\begin{array}{l}\text { Max house stocking density } \\
\text { (fixed housing) }\end{array}$ & $34.0 \mathrm{~kg} \mathrm{LW} / \mathrm{m}^{2}$ & $\begin{array}{l}13 \mathrm{~b} / \mathrm{m}^{2} \text { or } \\
27.5 \mathrm{~kg} \mathrm{LW} / \mathrm{m}^{2}\end{array}$ & $\begin{array}{l}6 \mathrm{~b} / \mathrm{m}^{2} \text { (layers) or } 10 \mathrm{~b} / \mathrm{m}^{2} \text { (fattening) } \max 21 \mathrm{~kg} \\
\mathrm{LW} / \mathrm{m}^{2}\end{array}$ \\
\hline $\begin{array}{l}\text { Max house stocking density } \\
\text { (mobile housing) }\end{array}$ & & & $16 \mathrm{~b} / \mathrm{m}^{2}$ (fattening) $\max 30 \mathrm{~kg} \mathrm{LW} / \mathrm{m}^{2}$ \\
\hline Flock size & Unlimited & Unlimited & $\begin{array}{l}4800 \text { chickens, } 3000 \text { layers or } 2500 \text { turkeys per } \\
\text { poultry house }\end{array}$ \\
\hline Access to range & Not required & $\begin{array}{l}\text { Continuous day time access } \\
\text { require or all least half their } \\
\text { lifetime }\end{array}$ & Weather permitting, for at least $1 / 3$ or their life \\
\hline Pasture allowance & None & $1 \mathrm{~m}^{2} /$ birds & So that not more than $170 \mathrm{~kg} / \mathrm{N} / \mathrm{ha} / \mathrm{yr}$ \\
\hline Feed specification & None & $\begin{array}{l}\text { Finisher contains at least } 70 \% \\
\text { cereals }\end{array}$ & $\begin{array}{l}\text { At least } 65 \% \text { cereals, no synthetic amino acids, } \\
100 \% \text { organic ingredients. However, a derogation } \\
\text { exists that allows } 20 \% \text { from non-organic sources }\end{array}$ \\
\hline
\end{tabular}

Intensive production is a very common and commercial process. In this process, chickens are raised up in a controlled environment and high nutrient feeding system. Breast meat is very popular in Ireland. That is why breeders are preferred which give a high amount of breast meat. Normally it takes 35 to 56 days to reach the weight $3 \mathrm{~kg}$ of chicken and in case of intensive egg production around 290 eggs can be collected per chicken per layer cycle.

Free range is also a popular system where chickens are allowed access to the outdoors. These birds take around 56 days to grow up. According to Teagasc (2006a) there are some regulations for free-range farming in Ireland. Those are i) chickens should be allowed daytime access for open-air running, ii) the ground should be covered with plant or grass, iii) the maximum stocking density has to be a thousand chickens per hectare, iv) an insulated house has to be made with a floor space of onemeter square per seven chickens (Teagasc, 2006a).

Label Rouge is a French pasture-based production arrangement. According to this system, there is some regulation for using feeding ingredients such as diets should contain $65 \%$ cereal. At six weeks age a ring is worn on the pullet's wing by the certifying organization. The density has to be 13 pullets per $\mathrm{m}^{2}$. Normally chicken lays after 21 weeks when it will go through a complete light and nutrition program.

Organic table birds and layers are very popular in whole Europe. It must be maintained by the European council regulations and examined by certifying bodies of each country. In Ireland, there are three organic certification constitutions.

1. Demeter standards

2. Irish organic farmers and growers association

3. Organic trust (Teagasc, 2006b)

Around 29850 ha agricultural land was used for organic food in 2002 in (DAF, 2002). Most of the organic foods in Ireland are fruits and vegetables. Organic meat mainly beefs and lambs are occupied $25 \%$ of the organic food. Organic poultry and egg are negligible due to the limited supply (DAF, 2002). Table 1 shows the total number of producers and birds involved in organic poultry production in Ireland in 2002. 
The market for organic poultry feed is very small. Hence only one supplier is available all over Ireland (Teagasc, 2006b). This feed is very expensive almost $80 \%$ expensive than normal poultry feed. This feed must be free from any types of genetically modified organisms. Chickens which are produced for organic meat production requires 81 days to grow up which is a lengthy procedure (Teagasc, 2006b).

Table 1. Total number of producers and birds in 2002, Ireland

\begin{tabular}{lcc}
\hline & $\begin{array}{c}\text { Total number of } \\
\text { producers* }\end{array}$ & Total number of birds \\
\hline Broiler hens & 11 & 1,935 \\
Laying hens & 64 & 18,793 \\
Turkeys & 5 & $* *$ \\
\hline * Producers with poultry numbers or 10 or more** insufficient data. \\
Source: Anon (2002)
\end{tabular}

\section{European and Irish policies and legislation}

In Europe union, the poultry meat production is directed by the European communities (fresh poultry meat) regulations 1996 (S.I. No. 3/1996) and council directive 71/118/EEC European Economic Community (EEC) (Directive, 1996). This regulation controls the premises approval, application of the health mark to poultry, hygiene and sanitary standard etc. European communities (marketing standards for poultry meat) regulations 2002 (S.I. No 440) cover the marketing standards such as labelling, grading by quality etc. (Magdelaine et al. 2008).

The Poultry hatcheries act 1947 and the poultry hatcheries regulations, 1959 controls about the breeding stock as they should be collected from permitted breeding sources. It also controls the inspection and blood testing to keep poultry free from diseases (HARRIS, 1973).

European communities (marketing standards for eggs) regulations, 254/1992 implementing regulation (EEC, No. 1907/90) and regulation (EEC, No. 1274/91) deals with egg grading, weighing, packing, labelling, transporting and marketing. The egg for incubation is not allowed for human consumption (EISB, 1992b).

European communities (egg products) regulations 1991 (S.I. No. 293 of 1991) and European communities (egg products) regulations 1992 (S.I. No. 419 of 1992) implementing council directive No. 89/437/EEC deals with hygiene, supervision, marking, marketing of egg products (IRL, 1991).

According to Ireland rules and regulation, if anybody is going to deal or trade poultry for commercial or noncommercial basis has to be certified with the department of agriculture, fisheries and food under the diseases of animals act 1966 (registration of poultry premises) order 2008 (S.I. No. 42 of 2008 as amended by S.I. No. 57 of
2011). And that person must be committed to the rules of biosecurity and record keeping requisites (DAFM, 2013)

The regulation for poultry manure is written in statutory instruments S.I. No. 378 of 2006. All the requirements are written here for that person who will apply for Integrated Pollution Prevention and Control (IPPC) license. The Environment Protection Act, 1992 is required for the following activities (EISB, 1992a).

1. Any type of emission cannot violate the air quality standard enumerated under section 50 of air pollution act, 1987.

2. Any type of emission cannot violate the quality standard of waters, trade effluents and sewage which is enumerated under section 26 of the local government (water pollution) act, 1977.

3. Any type of emission from the action of plant, methods or procedure cannot violate the rules of European communities act, 1972.

4. Any noise cannot violate the rule under section 106.

Environmental protection agency act 1992 (established activities) order, S.I. No. 279 of 2006 deals with poultry installation in Ireland (Intertradeireland, 2011). The key legislative concerned to poultry production in Ireland is actually characterized by the following standards:

1. International quality management standards as for example ISO 9001:2000

2. Hazard analysis and critical control points as summarized by Codex Alimentarius (1997)

3. Compatible national and Europe union legislative requirements involving European Commission(EC) 178:2002 and EC 852:2004

4. EN 45001 (1998) general requirements of bodies who are involved in product certification systems (Bord Bia, 2008).

\section{Carbon footprint during poultry production}

According to food and agriculture organization report "livestock long shadow; environmental issues and options" livestock production is one of the main issues for the environment. The report showed that around 18\% Greenhouse Gas (GHG) emissions come from livestock (FAO, 2006). GHG is lower in pork and poultry for the adequate digestion process and inexistence of enteric fermentation process. And the GHG emission is lower in poultry comparing to pork. In the European Union considering product level 19 to $28 \mathrm{~kg} \mathrm{CO} 2$-equiv. per $\mathrm{kg}$ of meat (beef, sheep and goat) is the total GHG intensity. Comparing that amount poultry gives only $5-7 \mathrm{~kg} \mathrm{CO} 2-$ equiv. which is less. The emission of $\mathrm{CH} 4$ and $\mathrm{NO}$ is high 
for poultry production. Egg considerably gives lower carbon footprint. In Europe, union egg production causes a net emission of $2.8-3.2 \mathrm{~kg}$ of $\mathrm{CO} 2$-equiv. per $\mathrm{kg}$ of eggs. In Ireland, poultry meat production emits $3.3 \mathrm{~kg} \mathrm{CO} 2-$ equiv. per kg of poultry (Weiss and Leip, 2012).

Jacob (2009) showed the average GHG emission in a broiler industry. He stated that 5.5 tons $\mathrm{CO} 2$ emission happens for 1000 broilers marketed, $7.5 \mathrm{lbs} \mathrm{CH} 4$ emission occurs per thousand broilers marketed and $3.8 \mathrm{lbs} \mathrm{N} 2 \mathrm{O}$ emission occur for thousand broilers marketed.

The carbon footprint of Ireland in the livestock sector is always lower than any other country in Europe union. Joint research center of the European Union commission published major research in which Ireland is rated amongst the best for the carbon footprint (Teagasc, 2011). The research entitled "evaluation of the livestock sector contribution to the Europe Union GHG emissions" demonstrated the carbon emission of livestock products, the production of feeds. It also reported the emission due to an input of mineral fertilizer, pesticides, energy etc. from this study, the poultry carbon footprint was $3.3 \mathrm{~kg}$ $\mathrm{CO} 2$-eq per $\mathrm{kg}$ of poultry where the average value of carbon footprint in European Union is $4.9 \mathrm{~kg} \mathrm{CO} 2$-eq per $\mathrm{kg}$ of poultry (Teagasc, 2011).

From figure 1, it can be easily noticed that among the other European countries the emission of GHG in Ireland for egg production is really low. It is near about $2.5 \mathrm{~kg}$ $\mathrm{CO} 2$-equiv. per $\mathrm{kg}$ of product. From figure 2, it also can be easily noticed that the position of Ireland for poultry meat production is really not the alarming phase. Ireland is in the lowest position for the emission of GHG in case of poultry meat production

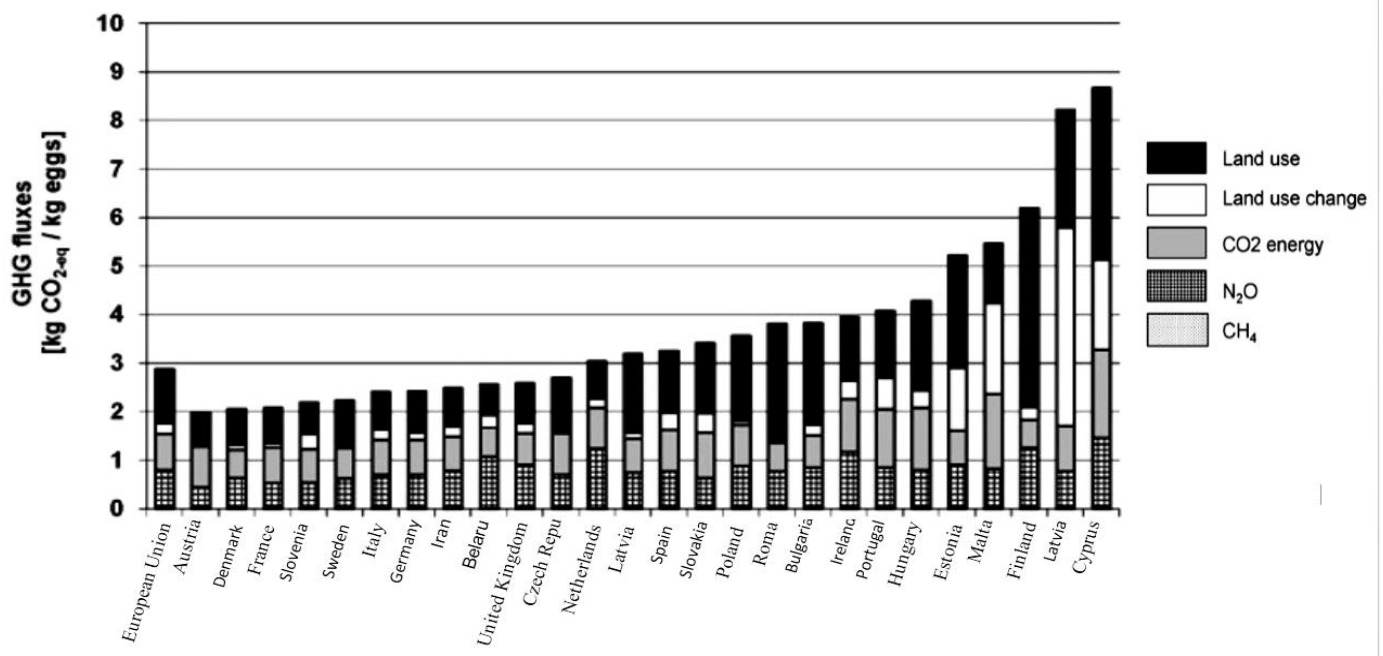

Figure1. GHG fluxes of eggs (in $\mathrm{kg} \mathrm{CO}_{2}$-equiv. per kg of product), European Union (27 countries), 2004 (Source: Weiss and Leip, 2012).

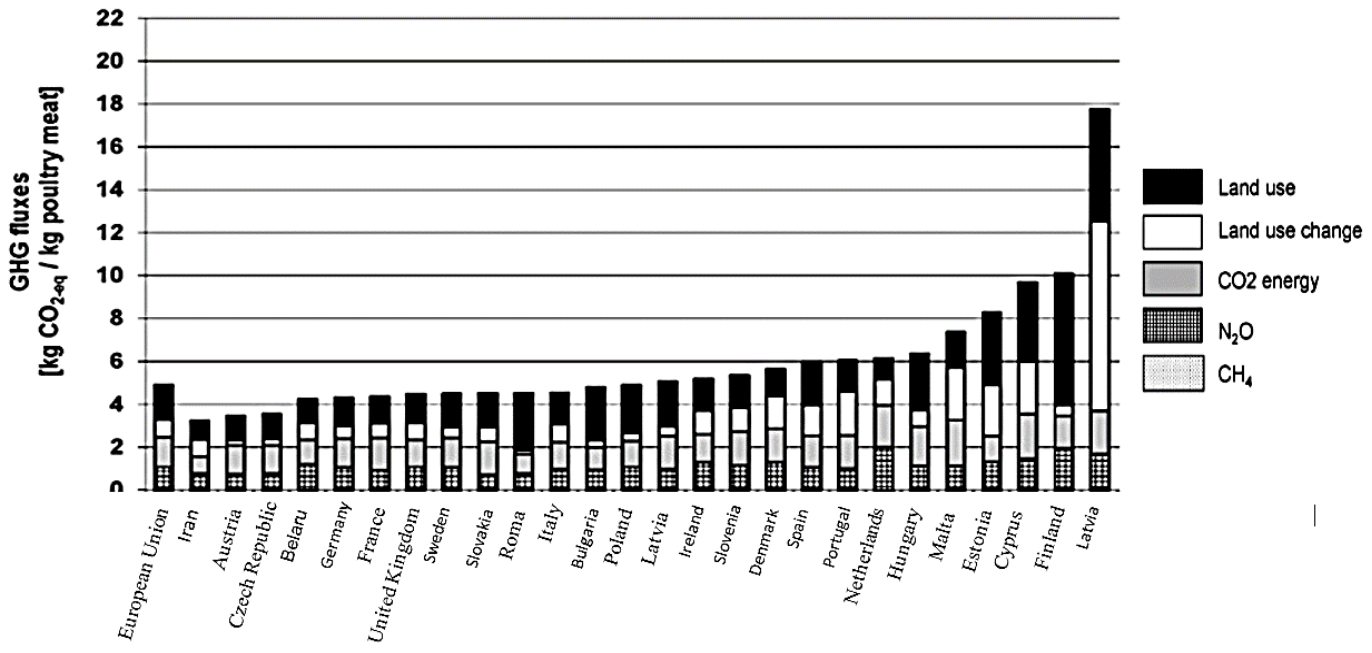

Figure 2. GHG fluxes of poultry meat (in kg CO2-equiv. per kg of product), European Union (27 countries), 2004 (Source: Weiss and Leip, 2012) 


\section{Environmental Issues}

In a poultry processing area, some factors are very important to control environmental hygiene. The factors are exterior structure and grounds, interior structure, interior walls, ceiling and overheads, floors, drainage, doors, windows, lighting, water and water supply, knives, sterilizers, hoses and other equipment, extraction and ventilation, cleaning materials and storage, food trays, electronic fly killers, effluent treatment and complete waste disposal system (FAO, 1996).

Mainly two important parts are important for ecological aspects. One is the production of concentrated feed and another is the generation of GHG through chicken processing and transporting of processed product.

\section{Environmental impacts of poultry feed production}

The feeds for poultry consist of main cereals, soy, oilseeds and pulses. Intensive feed production effects negatively to the land and water. To produce high crop yield mineral fertilizer, pesticides and different herbicides has to be used intensively which pollute the environment. Smil (1999) reported that 30-50\% of nitrogen fertilizer and $45 \%$ of phosphorus fertilizer is absorbed by the plant. For feed production in the world, about 20 million tons of nitrogen fertilizer is used and $36 \%$ of that feed is produced as poultry feed. This also causes serious air pollution because of the volatile nature of ammonia. Feed production also affects negatively in biodiversity. The increasing demand for feed requires expansion of cropland and thus it affects through the adaptation of natural habitats. Sometime overexploitation of fisheries is happening for producing the fishmeal for the poultry (Steinfeld et al., 2007).

\section{Environmental impacts on poultry manure}

The growing poultry industries are giving serious concern about poultry waste mainly poultry manure. Poultry litter is a very good origin of organic fertilizer. But this poultry manure creates some environmental problems such as nitrite that extracted into the groundwater, phosphorus from poultry manure mixes up with surface water bodies and various pathogenic organism released by poultry manure. The most important thing to the poultry manure management system is to keep the manure dry as early as possible (Moore et al., 1995).

\section{Environmental impacts on air quality}

In chicken production houses three gases are of greatest concern. Those are ammonia, carbon dioxide and carbon monoxide. Table 3 revealed that both long and short term $\mathrm{CO}_{2}$ produce significantly had high amount than ammonia and Carbon monoxide. These gases negatively impact on human health.

Table 3. The following level has been observed for the protection of human health

\begin{tabular}{lcc}
\hline Name of Gas & $\begin{array}{c}\text { Long Term } \\
\text { Exposure Limit } \\
\text { (8 hours a day) } \mathbf{~ p p m}\end{array}$ & $\begin{array}{c}\text { Short Term } \\
\text { Exposure Limit } \\
(\mathbf{1 0} \text { minutes) } \mathbf{~ p p m}\end{array}$ \\
\hline Ammonia & 20 & 35 \\
Carbon monoxide & 50 & 400 \\
Carbon dioxide & 3000 & 5000 \\
\hline
\end{tabular}

Source: Bord Bia, 2008

Personnel-related to poultry production systems have to be aware of the location and production so that the air emission does not hamper the local environment. To establish a new production, house a producer can reduce problems related to the environment in many ways such as proper ventilation system, cover poultry litter, the proper management system of wastewater and waste packaging material, transporting through proper vehicle etc. Producers and processor should be careful because if they cross the limit they will need EPA license.

\section{Prevention of poultry waste production}

Industrial poultry waste management; in the poultry processing industry, various waste products are produced which have to be managed or processed for the safety of the environment. Some common practices are discussed here:

In a modern plant, flow-away systems are being used for fast and adequate processing. To reduce blood loss before killing stunning should be done. If stunning is not done blood may be spattered over a large area and deteriorate feathers. Dry cleaning is important before washing the whole receiving area. Feathers which are recovered can be disposed of or cooked by pressure to hydrolyze the keratin protein. Screened water should be used in the de-feathering operation. Feet, head, viscera and other parts which are inedible should be gathered for disposal or inedible analysis. Final evisceration wash water can be re-used for other unimportant sub-processes. The special nozzle should be used to reduce the wastage of water (FAO, 1996).

\section{Wastewater management}

Wastewater from the poultry processing industry causes a serious environmental impact. It mainly hampers the natural environment in three ways. The waste water contains a lot of biodegradable compounds which reduce the dissolved oxygen in the water. Water containing 
reduced dissolved oxygen is very harmful to aquatic life. Eutrophication may occur due to the presence of macronutrients such as nitrogen, phosphorus in the water bodies. Excess algae growth and their consecutive dying release too much mineral in water which also affects harmfully to the aquatic life. Some effluent compounds directly harm aquatic life such as un-ionized ammonia (Demayo et al., 1982). In the poultry processing industry, the offal flumewater contains one-third of the total waste load. It has been reported that the average value of biological oxygen demand (BOD) is $3.4 \mathrm{~kg}$ per ton of LWK (live weight killed). The highest BOD is found in chicken blood around $4.5 \mathrm{~kg}$ BOD per ton of LWK. The detailed values are showed in table 4.

Scalding is the processing step in which maximum energy consumption takes place. The scalding tank which contains residues and feathers holds 0.6 to $3.1 \mathrm{~kg}$ BOD per ton of LWK. In the chilling process, the overflow water contains 0.4 to $2.5 \mathrm{~kg}$ BOD per ton of LWK. Final wash water holds $0.7 \mathrm{~kg}$ BOD per ton of LWK. About half of the BOD comes from cleaning operation in a poultry processing industry (FAO, 1996).

Table 4. Different components of poultry slaughterhouse, European Union, 1973

\begin{tabular}{lcc}
\hline \multirow{2}{*}{ Components } & \multicolumn{2}{c}{ Poultry slaughterhouses } \\
\cline { 2 - 3 } & Chicken Range (kg/Ton) & Turkey Range (kg/Ton) \\
\hline Biological oxygen demand & $3.3-25$ & $1-9$ \\
Chemical oxygen demand & $5.9-45$ & $1.8-16$ \\
Kjeldahl nitrogen & $0.15-12.2$ & $0.4-1.9$ \\
Suspended solid & $0.1-22$ & $0.6-10.9$ \\
Phosphorus & $0.054-2.5$ & $0.034-0.2$ \\
\hline
\end{tabular}

Source: Verheijen (1996).

\section{Manure management}

Statutory Instruments S.I. No. 378 of 2006 deals with poultry manure management. The litter from the poultry farm should be stored in the litter storage shed. That shade should have 347-meter square floor area. Shed also contains a ditch for wash-waster holding. That ditch should be the 8.1-meter cube. Normally 1-meter cube space is needed for $600 \mathrm{~kg}$ of litter. A contractor will provide all the necessary things like machinery or labor to clean the houses and transfer the litter to the storage shed (EPA, 2009).

\section{Emissions minimization}

Emission to air, water or land that occurred for poultry housing can be prevented or minimized in many ways. Walls and roofs in the poultry house should be properly insulated and smooth enough for cleaning easily. The building should be waterproof. Forced air drying system should be used to dry manure rapidly on belts. This drying and stabilization will reduce flies. Gable fan and air inlet should be conducted electronically. Gable fan will be only operated when the temperature will rise more than 25 ${ }^{\circ} \mathrm{C}$. Fans should be adapted with light filters to minimize emissions. Fans should be cleaned on a regular basis. Nipple drinker system should be used to minimize water wastage and to manage dry manure to reduce the emission of ammonia. Low energy lighting should be used. A review of housing and overall management should be carried out after 12 months and after following that review developed method should be implemented for the next year.

Manure should be dried instantly within 24 hours for volatilization of ammonia. Dried manure should be sent to manure store (Alberta, 2008).

\section{Energy minimization}

The artificial heating system is not commonly adapted for the layer farms because of high stocking density and low temperature. Common activities regarding energy requirement are heating the water in the winter season, distributing system of feed, ventilating the house, lighting (high energy consumption requires here), collecting and sorting of eggs and packaging. On the other way, in a broiler farm energy requires for the heating system which is being done initial phase, preparing and distributing of feed and ventilating of the house which is weather dependent.

To reduce the energy consumption for poultry production some methods can be applied, such as highquality insulation in walls and roof, automatically ventilation and constant temperature controlled systems. On the other hand, in the feeding system, power consumption can be increased if high friction occurs. So effective and automated feeding system installation is necessary to minimize the energy consumption (Baxevanou et al., 2017). 


\section{Effective measures to monitor emissions}

\section{Emissions to air}

Sometime incinerator should be used to burn carcass. Small incinerator (less than $50 \mathrm{~kg}$ per hour) should be used. The temperature inside the incinerator should reach to $85{ }^{\circ} \mathrm{C}$ for complete combustion. Monthly checking is necessary for the incinerator.

\section{Emission to water}

The dry cleaning system is used which remove completely the contaminated run-off. Sometimes it is passed directly from hard standing region to waste water tank. According to the code of good practice, the wastewater tank should be emptied to thoroughly clean up. Record keeping should be done with checking or emptying of the tank (Sparrey, 1994).

\section{Emission to land}

Discharging of ammonia and dust from the air and spreading manure on soil may be the reasons for emissions to land (Sharp, 2006).

\section{Odour minimization}

The odour of poultry waste may be minimized by taking some steps. Effective dry manure system is maintained with controlling humidity, temperature and prevent leakage at the water supply system. High standard of cleanliness should be maintained by regularly cleaning up deposited dust, the dead body removes and controlling internal weather condition. For preventing feed wastage storage bins should be sealed (Ranadheera et al., 2017).

\section{CONCLUSION}

Ireland is the highest position for consuming poultry meat among other European countries and on the other hand, this country has the lowest position for emission of greenhouse gases for poultry meat production. Here chicken meat production emits $3.3 \mathrm{~kg} \mathrm{CO}_{2}$-equiv. per $\mathrm{kg}$ of poultry. So the situation is not critical yet. But it is going to be critical soon if the necessary preventive measure will not be taken in the near future. Consumption of poultry meat is increasing daily. The new technologies are being used which consequently increase GHG. Intensive poultry production is popular here which gives fewer GHG compared to free-range poultry production. Through maintaining the rules and legislation for poultry farming in Ireland, it is very much possible for the poultry farmers to expand their business. Not only the poultry production industries but also the poultry processing industries need to be concern about ecological aspects.
They produce the largest amount of BOD in the whole processing systems. Effective poultry feed production, energy consumption in both poultry production and processing area, manure management system, wastewater and odour management system all these are very importantly handled as these systems are directly affiliated to the environment. Proper knowledge on the current scenario of poultry production in Ireland with ecological concern and the proper guidance with European and Irish policies and legislation are the basic need to expand this sector.

\section{DECLARATIONS}

\section{Acknowledgements}

The authors thank the department of nutrition and food engineering and the library of Daffodil International University for all kind of academic supports. Authors also acknowledge Dr. Md. Bellal Hossain, Head, Department of Nutrition and Food Engineering, Daffodil International University for his help and support.

\section{Competing interests} interests.

The authors declare that they have no competing

\section{Authors' contributions}

A K M Sarwar Inam and John Kearney designed the experiments and performed the experiments. A $\mathrm{K} \mathrm{M}$ Sarwar Inam and Md Suzauddula analyzed the results, drafted and revised the manuscript. Finally, all authors have read and approved the final manuscript and consent to publish in JWPR.

\section{REFERENCES}

Anon (2002). Census of Irish Organic Production 2002. The Department of Agriculture and Food. Available at http://www.agriculture.gov.ie/organics/Organic_CensusLaunched_9_Oct_03.pdf; Accessed 20 January, 2013.

Alberta Agriculture and Forestry, Trade and Environment Division, Environmental Stewardship Branch, \& Environmental Strategy and Research Section. (2008). Ammonia Volatilization from Manure Application. Retrieved December 11, 2018, Available at https://www1.agric.gov.ab.ca/\$department/deptdocs.nsf/all /agdex12064

Bord Bia (2008). Bord Bia: Irish Food Board. Poultry Products Quality Assurance Scheme: Poultry Producer Standard. Available at www.bordbia.ie; Accessed 22 January, 2013.

Bia B (2016). Export Performance and Prospects 2015/2016. Bord Bia, Dublin, Ireland, 16.

Baxevanou C, Fidaros D, Bartzanas T and Kittas C (2017). Energy Consumption and Energy Saving Measures in Poultry. Energy and Environmental Engineering, 5(2): 2936. DOI: 10.13189/eee.2017.050201

Codex Alimentarius (1997). Hazard analysis and critical control point (HACCP) system and guidelines for its application. 
ANNEX to Recommended International Code of Practice/ General Principles of Food Hygiene. CAC/RCP 1-1969, Rev 4. FAO/WHO Codex Alimentarius Commission. Retrieved

from www.fao.org/input/download/standards/23/CXP_001e.pdf (Page no. 21-31)

Intergovernmental Panel on Climate (IPOC) (2007). Climate change 2007: The physical science basis. Agenda, 6(7): 333.

DAF (2002). Department of Agriculture and Food. Census of Irish Organic Production. Retrieved from https://www.agriculture.gov.ie/media/migration/farmingse ctors/organicfarming/publications/Organic_CensusLaunched_9_Oct_03.pdf

DAFM (2013). Department of Agriculture, Food \& the Marine, Ireland. Poultry. Retrieved March 19, 2019, from https://www.agriculture.gov.ie/media/migration/farmingse ctors/poultry/PressArticlePoultryLegislativeRequirements 160511.pdf

Directive C (1996). Council Directive 96/23/EC of 29 April 1996 on measures to monitor certain substances and residues thereof in live animals and animal products and repealing Directives 85/358/EEC and 86/469/EEC and Decisions 89/187/EEC and 91/664/EEC. OJ EC L, 125: 10-31.

Demayo A, Taylor MC, Taylor KW, Hodson PV and Hammond PB (1982). Toxic effects of lead and lead compounds on human health, aquatic life, wildlife plants, and livestock. Critical reviews in environmental science and technology, 12(4): 257-305. DOI:10.1080/1064338820938

Electronic Irish Statute Book (eISB) (1992a). Environmental Protection Agency Act, 1992, Section 83. Retrieved December 23, 2018, Available at: http://www.irishstatutebook.ie/eli/1992/act/7/enacted/en/in dex.html

Electronic Irish Statute Book (eISB). (1992b). European Communities (Marketing Standards For Eggs) Regulations, 1992. Retrieved December 23, 2018, Available at: http://www.irishstatutebook.ie/eli/1992/si/254/made/en/pri nt

Food and Agriculture Organization (FAO) (1996). Food and Agriculture Organization. Management of Waste from Animal Product Processing. Available at: http://www.fao.org/WAIRDOCS/LEAD/X6114E/x6114e0 0.htm\#Contents, Accessed 22 January, 2013.

Food and Agriculture Organization.org. (2009). The State of Food and Agriculture 2009. [online] Available at: http://www.fao.org/docrep/012/i0680e/i0680e00.htm, Accessed 30 Nov. 2018.

HARRIS A (1973). BRITISH POULTRY HEALTH REGULATIONS. In European Poultry Conference (p. 431). British Poultry Science Limited.

Inter-Trade Ireland (2011). Inter Trade Ireland. Environmental Regulations and Cross-Border Trade and Business. Available at www.intertradeireland.com, Accessed 22 January, 2013.

Jacob J (2009). Poultry's Carbon Footprint. Cheeps and Chirps: Points for poultry profitability. 2(4): 3-5.

Joint Research Center (JRC) (2010). European Commission.
Evaluation of the livestock sector's contribution to the EU greenhouse gas emissions. Final report, 1-323.

Kearney J (2010). Food consumption trends and drivers. Philosophical Transactions of the Royal Society of London B: Biological Sciences, 365(1554): 2793-2807. DOI: $10.1098 /$ rstb.2010.0149

Lampkin N.(1997). Organic poultry production. Final report to MAFF. Aberystwyth, Welsh Institute of Rural Studies, University of Wales.

McCarthy M, O'Reilly S, Cotter L and de Boer M (2004). Factors influencing the consumption of pork and poultry in the Irish market. Appetite, 43(1): 19-28. DOI: 10.1016/j.appet.2004.01.006

Moore PA, Daniel TC, Sharpley AN and Wood CW (1995). Poultry Manure Management: Environmentally Sound Options. Journal of Soil and Water Conservation, 50 (3): 321-327.

Magdelaine P, Spiess MP and Valceschini E (2008). Poultry meat consumption trends in Europe. World's Poultry Science Journal, $64(1)$ : DOI:10.1017/s0043933907001717

Paul BK (2010). Factors Affecting Infant Mortality in Rural Bangladesh: Results from a Retrospective Sample Survey1. Rural Sociology, 55(4): 522-540. Doi:10.1111/j.1549-0831. 1990.tb00695.x

Ranadheera CS, Mcconchie R, Phan-Thien K, and Bell T (2017). Strategies for eliminating chicken manure odour in horticultural applications. World's Poultry Science Journal, 73(2): 365-378. DOI:10.1017/S0043933917000083

Republic of Ireland (IRL) (1991). European Communities (Egg Products) Regulations. Retrieved March 19, 2019, from http://www.legislation.ie/eli/1992/si/419/made/en/print

Sharp MJ (2006). Pollution Prevention and Control (Northern Ireland) Regulations 2003 Application for a Permit Example of Supporting Documentation - Laying Hens. Northern Ireland Environment Agency. Available at http://www.ni-environment.gov.uk, Accessed on 24 January, 2013.

Smil V (2000). Phosphorus in the environment: Natural Flows and Human Interferences. Annual Review of Energy and the Environment, 25(1): 53-88. DOI: 10.1146/annurev.energy.25.1.53

Steinfeld H, Wassenaar T, Gerber P, Verburg PH, Rosales M and Ibrahim M (2007). Projecting land use changes in the Neotropics: the geography of pasture expansion into forest. Global Environmental Change, 17(2): 86-104. DOI: 10.1016/j.gloenvcha.2006.03.007

Teagasc (2006a). Free Range Egg Production. Fact Sheet No. 14, May 2006. Available at http://www.teagasc.ie, Accessed on 20 January, 2013.

Teagasc (2006b). Organic Poultry. Fact Sheet No. 56, May 2006. Available at http://www.teagasc.ie, Accessed 20 January, 2013.

Teagasc (2011). Ireland Best in EU for Carbon Footprint of Milk, Pork, and Poultry Meat. Available at http://www.teagasc.ie/news/2011/201102-15.asp, Accessed 20 January, 2013.

Teagasc (2012). Agriculture in Ireland: The Irish Agri-Food 
Industry. Available at http://www.teagasc.ie/agrifood/, Accessed 20 January, 2013.

Sparrey JM and Kettlewell PJ (1994). Shackling of poultry: is it a welfare problem?. World's Poultry Science Journal, 50(2): 167-176. doi:10.1079/wps 19940014

Verheijen L, Wiersema D, Pol LH, Brandjes P, Meer HV, Westra $P$ and Bos JJF (1996). Livestock and the Environment: Finding a Balance: Management of Waste from Animal Product Processing. Staff Publications. Retrieved December 22, 2018, Available at http://library.wur.nl/WebQuery/wurpubs/487213

Weiss F and Leip A (2012). Greenhouse gas emissions from the EU livestock sector: A life cycle assessment carried out with the CAPRI model. Agriculture, Ecosystems and Environment, 149: 124-134. DOI:10.1016/j.agee.2011.12.015 